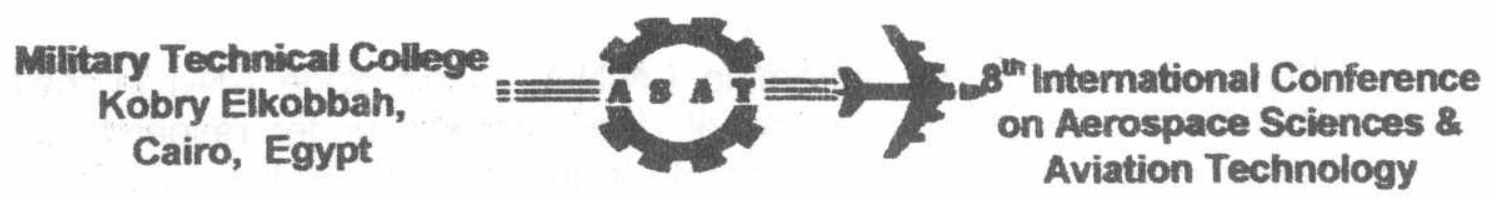

\title{
PREPARATION AND INVESTIGATION OF AZIDO HYDROXY TERMINATED POLYBUTADIENE
}

\author{
M.A SADEK *, M.SH FAYED **, M.A RADWAN ** \\ AND M.A BORHAM **
}

\begin{abstract}
Composite solid rocket propellants based on hydroxy terminated polybutadiene (HTPB) have become the workhorse propellants in solid rocket motors world-wide. It was reported that polymers containing azide groups exhibit an interesting feature. On pyrolysis or combustion they liberate extra heat due to the scission of the azide bond which is highly exothermic. In this paper energetic polymeric binder based on azido hydroxy terminated polybutadiene (AHTPB) was proposed, prepared and characterized. The synthesis was started by brominating the commercial hydroxy terminated polybutadiene (HTPB), followed by its refluxing with sodium azide for about 30 hours. The investigated propellant formulations were based on mixtures of the prepared energetic binder (AHTPB) (13\%) with different nitrogen content, ammonium perchlorate $(71 \%)$ and Aluminum $(16 \%)$. The performance of these propellant formulations was deduced through a computer program. Also, the effect of nitrogen content variation of the polymeric fuel binder on the specific impulse and the adiabatic flame temperature was investigated.
\end{abstract}

\section{KEY WORDS}

HTPB, AHTPB, bromination, azidation, energetic polymeric binder, specific impulse and adiabatic flame temperature.

\section{INTRODUCTION}

In the field of rocket propellant devolopment, many research programs have been directed to the selection and inyestigation of rocket propellant based on new polymeric materials in order to improve the performance of these propellants. The polymeric binder in a composite propellant usually represent $10-15$ percent by weight[1] of the composition. This polymeric binder has great effects on the mechanical properties of the final material perhaps the most important of these properties is the elastomeric behaviour and dimensional stability [2] in addition to improving the mechanical properties. The research was also directed to make it highly energetic. In this respect, polymeric materials carrying energetic groups

* $10^{\text {th }} \mathrm{R}$ amadan.HTI, Egypt.

* Egyption MilitaryForces. 
as: nitro $\left(-\mathrm{NO}_{2}\right)$, nitrato $\left(-\mathrm{ONO}_{2}\right)$, nitramino $\left(-\mathrm{N}-\mathrm{NO}_{2}\right)$ and azide $\left(-\mathrm{N}_{3}\right)$ in their molecules $[3,4]$ were prepared and some of them are still under research. On pyrolsis or combustion, these groups liberate extra heat due to the scission on certain chemical bonds which are highly exothermic. In the last few years [5], new types of binder systems have been developed containing azido-, azido methylgroups as energetic materials [6]. Hydroxy terminated polybutadiene (HTPB) is an important polymeric fuel binder in modern solid rocket propellants, therefore it is necessary to improve the propellant performance. HTPB in contact with air (which is unavoidable) exhibits viscosity build-up and sometimes gelling. In order to prevent this problem antioxidants are often added to the resin. The residual double boncls located on the polymeric backbone are the active centers responsible for such gelling characteristics, so it was suggested to be replaced by the azide groups to reduce this viscosity build-up and to increase the liberated heat on combustion.

\section{EXPERIMENTAL}

\section{Material}

The chemicals used are of pure grades normally used in chemical laboratories. They were used without further purification, these chemicals are: Bromine $(\mathrm{Br})$ (Aldrich), n-Hexane $\left(\mathrm{C}_{6} \mathrm{H}_{14}\right)$ (Fisher), Ethanol- $\mathrm{C}_{2} \mathrm{H}_{5} \mathrm{OH}$-(Prolabo), Formamide $\left(\mathrm{HCCNH}_{2}\right)$ (Aldrich), p-xylene(El-Naser), Acetone (Colinbrook). sodium azide $\mathrm{NaN}_{3}(\mathrm{BDH})$ and HTPB (LTM).

\section{HTPB specification}

Chemical formula : $\mathrm{HO}-\left(\mathrm{CH}_{2}-\mathrm{CH}=\mathrm{CH}-\mathrm{CH}_{2}-\right)_{n}-\mathrm{OH}$

Hydroxyl number:1.05 mg equivallent $(\mathrm{OH}) / \mathrm{g} \mathrm{HTPB}$

Heat of formation of HTPB $\left(\Delta u_{f}\right)=-138 \mathrm{cal} / \mathrm{g}$.

Density (g/c.c): 0.9032

Composition Of HTPB: Cis $19 \%$, Trans $58 \%$, Vinyl $23 \%$

\section{Testing of bromine and HTPB solubility in different solvents}

In order to find the best solvent for both bromine and HTPB, several organic solvents were used. n-Hexane was the most suitable for both reactants as $20 \mathrm{~g}$ of bromine were dissolved in $50 \mathrm{mmil} \mathrm{n}$-hexane and $10 \mathrm{~g}$ of HTPB were dissolved in $125 \mathrm{ml}$ $n$-hexane. These represent the starting concentration of both reactants used in the synthesis.

\section{Proparation of azido hydroxy terminated polybutadiene}

Bromine solution ( $7 \mathrm{~g}$ bromine in $175 \mathrm{ml} \mathrm{n}$-hexane) was added dropwisely in a controlled rate of about one drop/two seconds to HTPB solution (40g HTPB in 500 $\mathrm{ml}$ ) in a 2-liter beaker at room temperature. The color of bromine solution disappears after each addition due to its reaction with the polymeric double bonds. The resultant colourless solution was transffered to a suitable conical flask and to which sodiurn azide $(4.75 \mathrm{~g}$ ) was added. The mixture was then refluxed on a water bath for 30 hours at a temperature of $50-65^{\circ} \mathrm{C}$. The reaction mixture was cooled and the 
solvent was partially evaporated using a rotary evaporator. The precipitated sodium bromide was then filtered and the residual solvent in the filterate was completely evaporated to obtain the crude azido hydroxy terminated polybutadiene, which is directly used in the formulations.

\section{Characterization of the prepared energetic polymeric binder}

The prepared bromo-, and azido-polymeric binders were analyzed by infrared spectroscopy and elemental microanalysis of $\mathrm{Br}$ and $\mathrm{N}, \mathrm{IR}$ analysis was determined by-a Perkin-Elmer model 3087 spectrophotometer. The results of these analysis were shown in fig1,fig2 and fig3. A computer program [6] was used to calculate the effect of the proposed formulations on both the specific impulse and the adiabatic flame temperature of the propellant based on this energetic binder(AHTPB).

\section{RESULTS AND DISSCUSSIONS}

Composite propellants which have been specially formulated on the basis of ammonium perchlorate, aluminium, and polybutadiene binders fulfil the demands of high specific impluse, high buring rate and high mechanical strength[7]. Butadiene prepolymer of a number averaged molocular weight $2500-3800$, provided a viscosity level required for its use as a fuel binder from which solid propellant can possibily made by means of direct casting method. In this way, an energetic binder can be regarded as any polymer or mixture which reacts exothermically and liberates high amount of energy and gaseous products. in this paper, it was suggested that the transformation of polymer binder (HTPB) to the energetic stage via its azidation. This azidation was proposed to proceed in two steps. The first one is the bromination of the HTPB by its addition to the double bond, and the second step is the conversion of the brominated polymer to the corresponding azido one through its refluxing with sodium azide in aprotic solvent for 30 hours at $50-65^{\circ} \mathrm{C}$, according to the following chemical equations

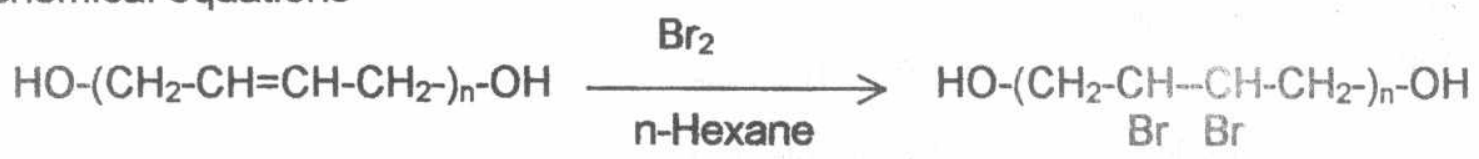

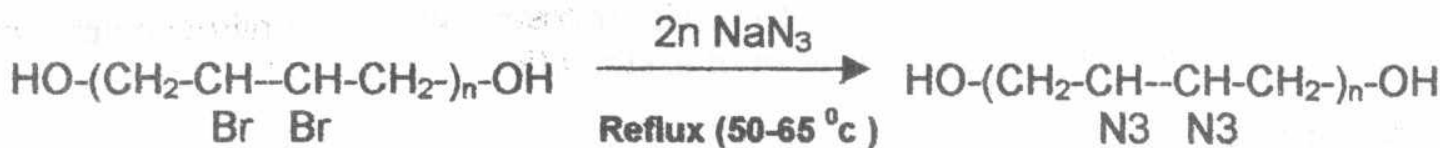

$$
\begin{aligned}
& +2 \mathrm{n} \mathrm{NaBr}
\end{aligned}
$$

The bromine soulution was added dropwise on the polymeric solution until a separation of the the brominated polymer occurs. This may be attributed to the difference in solubility parameters of both HTPB and its brominated one in n-hexane at the experimental conditions, so the resultant reaction mixture can be looked as a mixture of two prepolymers. According to the micro-elemental analysis mentioned before, this mixture was proposed to contain about $20 \%$ of the brominated one, this mixture was then refluxed as it is with sodium azide in $n$-hexane without its 
binder can be regarded as a mixture of about $20 \%$ azido form with the rest as unchanged HTPB. By this manner its energy characteristics are enhanced partially by this azidation process as it is indicated the calculation. The IR-spectrum of $\mathrm{HTPB}$ (in $\mathrm{KBr}$ disk) is shown in fig1. The presence of an absorption peak at $600 \mathrm{~cm}^{-1}$ in the IR-spectrum of brominated derivative shown in fig2, indicates the formation of $\mathrm{C}-\mathrm{Br}$ bond [8].This peak disappeared in fig3 representing the IR-spectrum of the azido polymer and was replaced by an absorption peak located at $2100 \mathrm{~cm}^{-1}$ characterstic of the azido group [9]. The same results were confirmed by the quantitative elemental analysis of both $\mathrm{Br}_{2}$ and $\mathrm{N}_{2}$ in the prepared polymeric binders. The nitrogen content was found to be $13.1 \%$, which is considered as an important factor in calculations.

\section{Performance of the rocket propellant based on AHTPB.}

The summary gram atomic composition was calculated based on one kilogram of propellant.The nitrogen percentage of one kilogram of AHTPEI was then estimated.The invstigated formulations were based on the energetic polymeric binder (AHTPB), ammonium perchlorate as oxidizer and aluminum as fuel. The performance was deduced using a computer program in which the adiabatic flame temperature and the specific impulse were calculated depending on the percentage composition of the prepared rocket propellant. The results are shown in table1, and represented graphically in fig4. these results show that the specific impulse is $252 \mathrm{sec}$ for HTPB and increases gradually with the azidation according to the nitrogen content. It reaches its maximum at a value of 272 sec for $18 \%$ nitrogen content. After that it starts to decrease also gradually with the increase in the nitrogen content. This may attributed to the high exothermicity of azide groups decomposition. This phenomena can be understood according to equation:

$$
\text { Is } \alpha \sqrt{T_{K} / M}
$$

Is ...... Specific impulse (second).

$T_{K} \ldots$.. Adiabatic flame temperature

M. Mean molecular mass of gaseous products

This equation relates the specific impulse(ls), adiabatic flame temperature( $\left.T_{K}\right)$ and the mean molecular weight of the formed gaseuos products(M). From fig3 it is clear that the adiabatic flame temperature $\left(T_{K}\right)$ increases with the nitrogen content cornpared with the formulation of HTPB without azidation.

\section{CONCLUSION}

The azido hydroxy terminated polybutadiene was successfully prepared in laboratory by treating the prepared brominated HTPB with sodium azide. The conversion was equal to 21 percent., the highest obtained value of the specific impulse is 
(Is =272 sec) compared with $250 \mathrm{sec}$ for HTPB, for $18 \%$ nitrogen content and decreases with further increase in nitogen percent. It is necessary to examine the viscosity of (AHTPB) with the increase in nitogen content, to evaluate the processing characterstics in future work. The prepared energetic polymeric binder AHTPB was characterized by different analytical methods as: elemental analysis, and IRspectroscopy. The specific impulse and the adiabatic flame temperature of the propellant formulations containing AHTPB vary with the nitrogen content. The highest value of the specific impulse (272 sec) was obtained at the value of nitrogen content equals $18 \%$. . The adiabatic flame temperature of the prpellant formulations increases with the increase of nitrogen content. The prepared azido polymer appears to be very suitable as a component for high energy polymeric binders in explosive and proppellant systems.

\section{REFERENCES}

1-Akira I, kazuo $\mathrm{H}$ and Tesue $\mathrm{T}$ " Hydrogenated Hydroxy Terminated Polyisoprene as Fuel Binder for Compsite Solid Rocket Propellants ", Propellants, Explosives and Pyrotechnics, vol.21(1), 43 (1996).

2-Achim P and Stefan L" Controlled Pyrolysis of the Energetic Binder Azid

Polyester", Propellants, explosives, and Pyrotechnics, vol22(3), 137 (1997).

3-Akira I, kazuo H and tesue T, Propellants, Explosives, and Pyrotechnics, vol.2, 108 (1989).

4-Manser G.E, Aerojet Solid propulsion, Scaramento, Califorina, 9552-1699, USA (1990).

5-Manser.G.E, Folsom. Fletcher.R.W and Fair O, US Pat.4707540(1987)

6-Moustafa A.H., "Investigation and Preparation of Modified Emulsion Explosive Mixtures", PhD, Thesis M.T.C (1994).

7-Thomas k and Friedrich.W, "Polymers with High Energy Substituent Polyester Containing Azido Methyl group * Propellants, Explosives and Pyrotechnics vol.17 (4), 183,(1992).

8-Klaus $M$ and Siegfried $E$. "Rocket propellant with reduced smoke and high buming rates "Propellants, Explosives, and Pyrotechnics, vol.22(3), 1112, (1997).

9-Jhon Mc.M, " Organic Chemistry “, $2^{\text {nd }}$ Edition, 397, (1988).

10-Carpenter, Analytical Chemistry, 36, 2352 , (1964), US patent 4405762, (1983). 
Table(1). Effect of Variation of Nitrogen Content of the prepared AHTPB On the Specilic; Impulse and Adiabatic Flame Temperature of Propellant Formulations Based on (AHTPB=13\% / Apowiter $=16 \% / \mathrm{AP}=71 \%$ ).

\begin{tabular}{|c|c|c|c|c|c|c|c|c|}
\hline \multirow[t]{2}{*}{ No } & \multirow[t]{2}{*}{$\begin{array}{l}\text { Conversion } \\
\text { percent of } \\
\text { AUTPB to } \\
\text { AHTP }\end{array}$} & \multicolumn{3}{|c|}{$\begin{array}{c}\text { gram atomic } \\
\text { composition of } 1 \mathrm{Kg} \\
\text { AHTPB }\end{array}$} & \multirow[t]{2}{*}{$\begin{array}{l}\text { N2 } \\
\text { weight\% }\end{array}$} & \multirow[t]{2}{*}{\begin{tabular}{|l}
$\mathrm{AHf}$ \\
$\mathrm{kcalkg}$ \\
(cal.)
\end{tabular}} & \multirow{2}{*}{$\begin{array}{c}\text { adiabatic } \\
\text { flame } \\
\text { temperature } \\
\text { (K) }\end{array}$} & \multirow[t]{2}{*}{$\begin{array}{l}\text { Specific } \\
\text { Impulse } \\
\text { Sec }\end{array}$} \\
\hline & & C & $\mathrm{H}$ & $N$ & & & & \\
\hline 1 & zero & 74 & 111.1 & 0 & 0 & -138 & 3504 & 254 \\
\hline 2 & 10 & 69.6 & 104.4 & 4.36 & 6.1 & -94.2 & 3541.9 & 261 \\
\hline 3 & 20 & 65.7 & 97.06 & 8.7 & 12.18 & -51 & 3592 & 270 \\
\hline 4 & 30 & 60.5 & 40.82 & 13.04 & 18.26 & -8.4 & 3625 & 272 \\
\hline 5 & 40 & 56.0 & 84.06 & 17.39 & 24.35 & 34.8 & 3654 & 271.3 \\
\hline 6 & 50 & 51.5 & 77.29 & 21.7 & 30.38 & 78 & 2681 & 270.3 \\
\hline 7 & 60 & 47.0 & 70.53 & 26.1 & 36.54 & 121.1 & 3711 & 270 \\
\hline 8 & 70 & 42.51 & 63.77 & 30.44 & 42.64 & 164.4 & 3746 & 269 \\
\hline 9 & 80 & 38 & 57 & 34.78 & 48.64 & 207.6 & 37771 & 268 \\
\hline 10 & 90 & 33.39 & 50.24 & 39.13 & 54.76 & 250 & 3778 & 267 \\
\hline 11 & 100 & 28.98 & 43.48 & 43.48 & 60.87 & 294 & 3820 & 265 \\
\hline
\end{tabular}

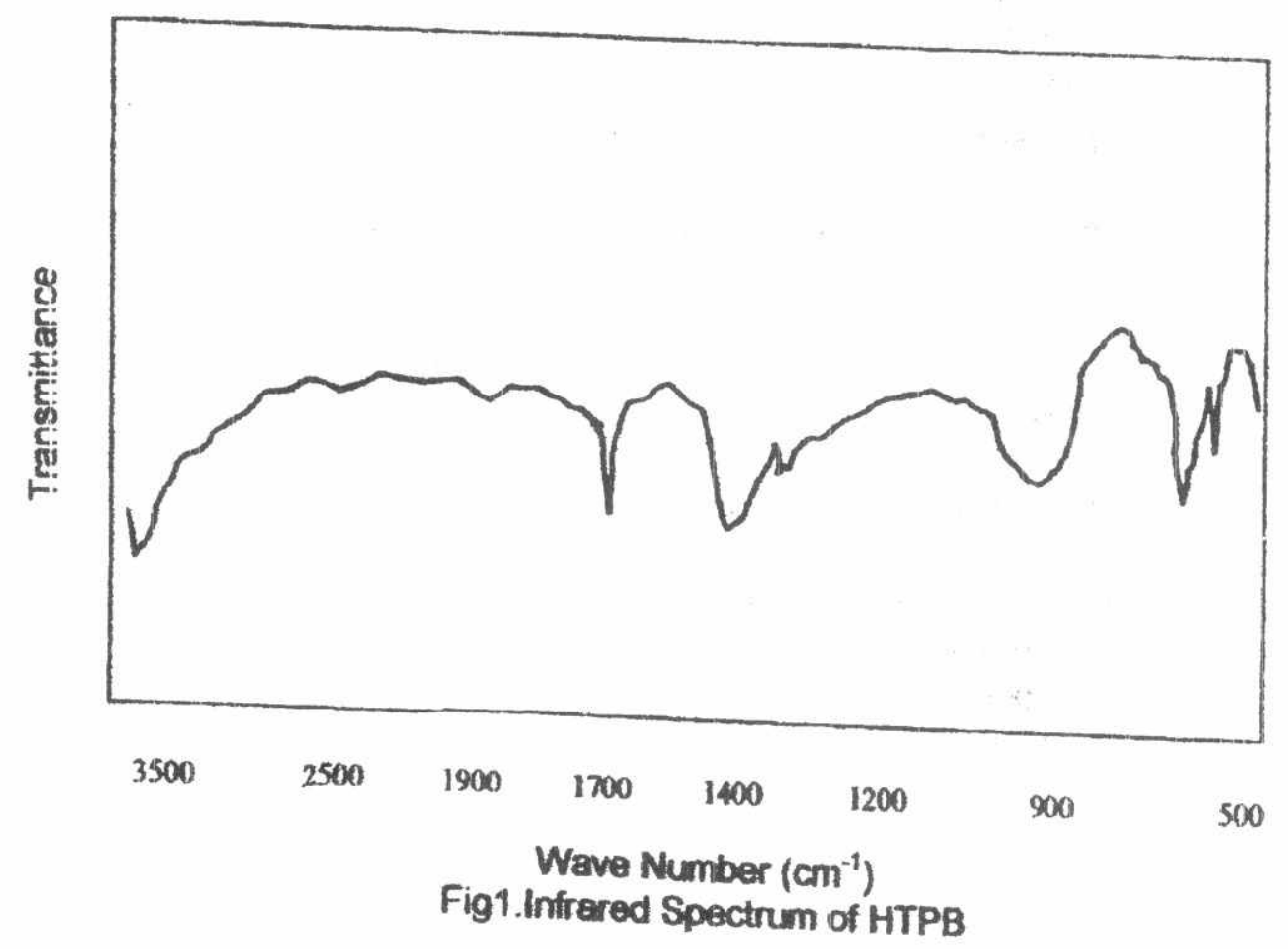




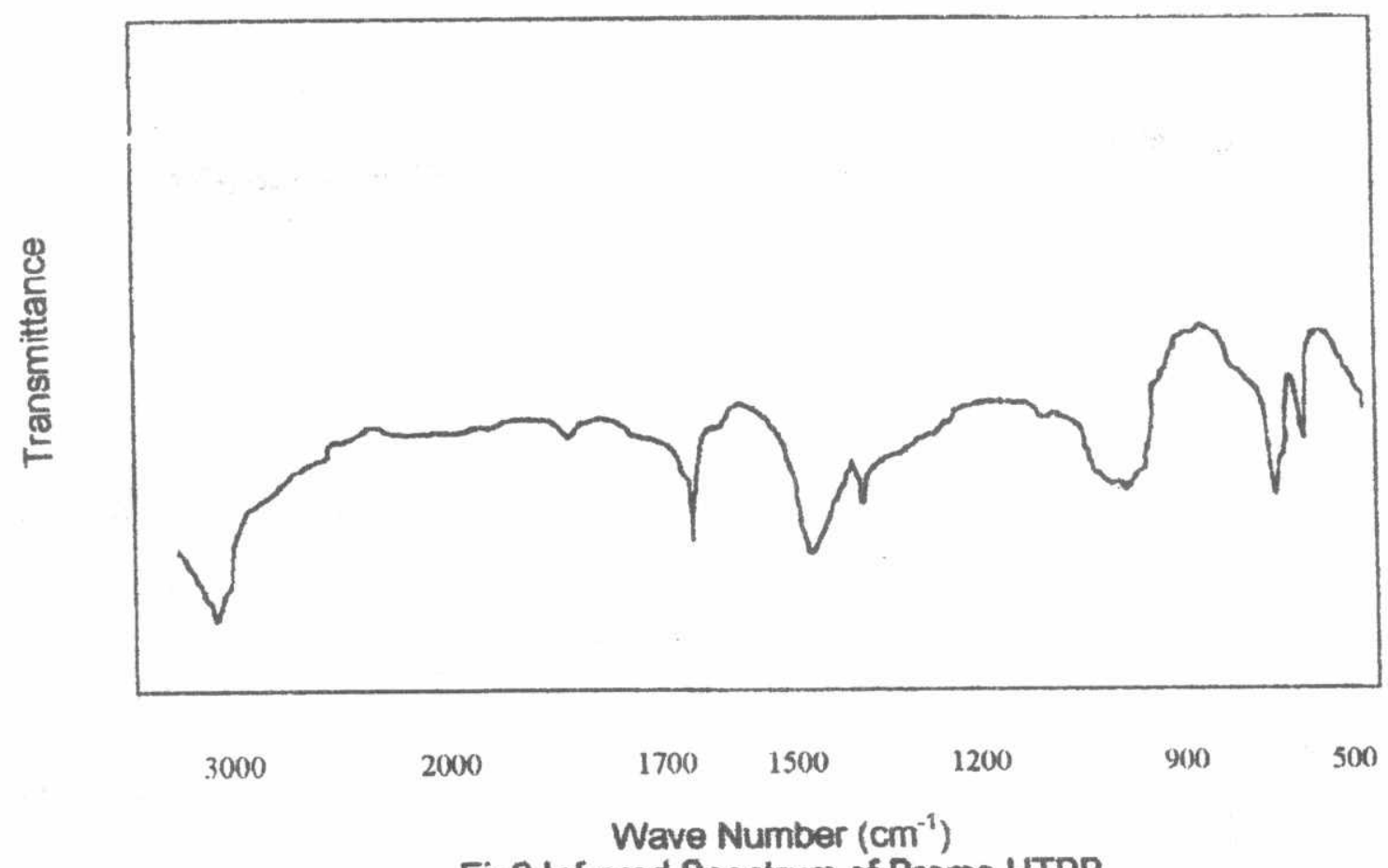

Fig2.Infrared Spectrum of Bromo HTPB

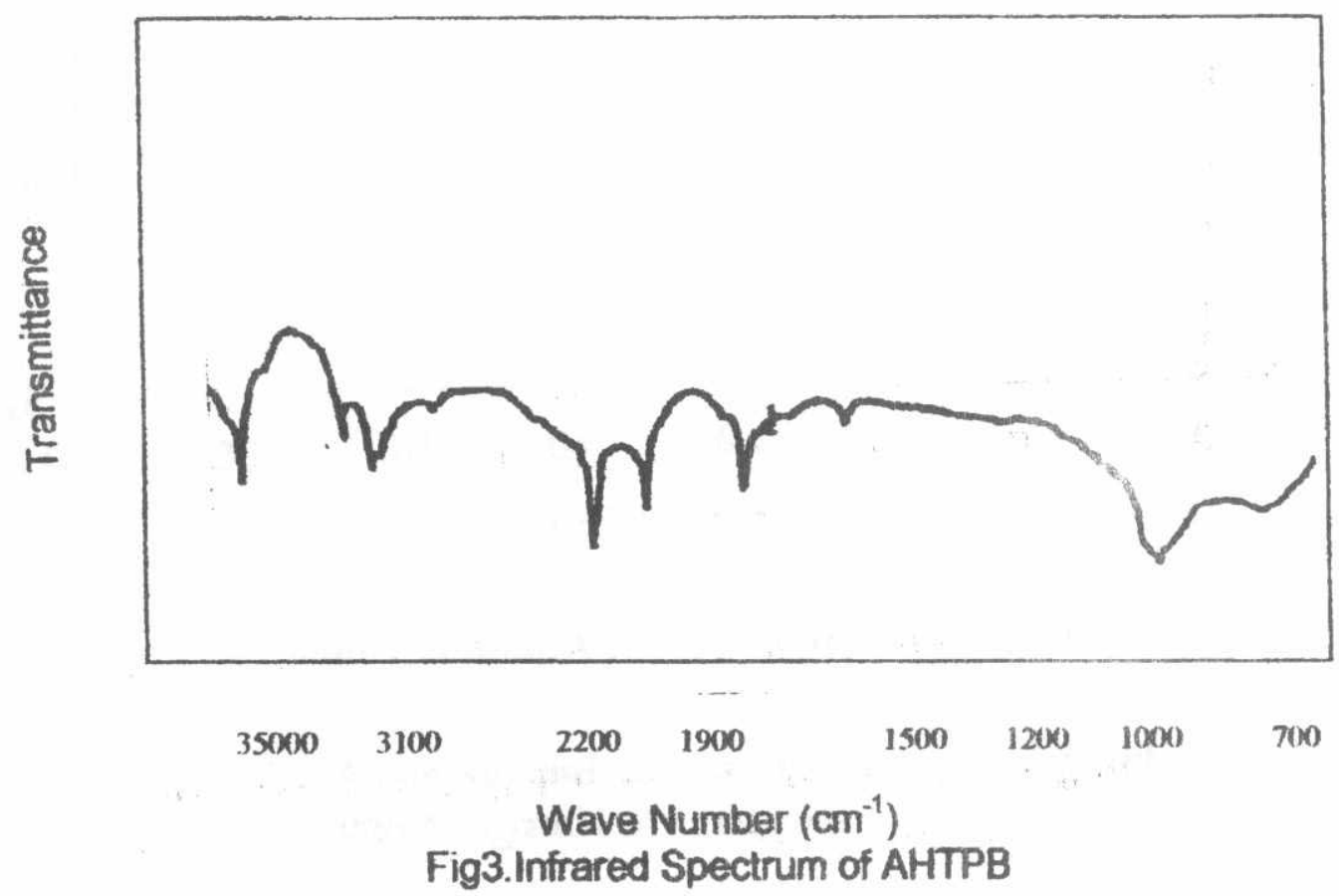




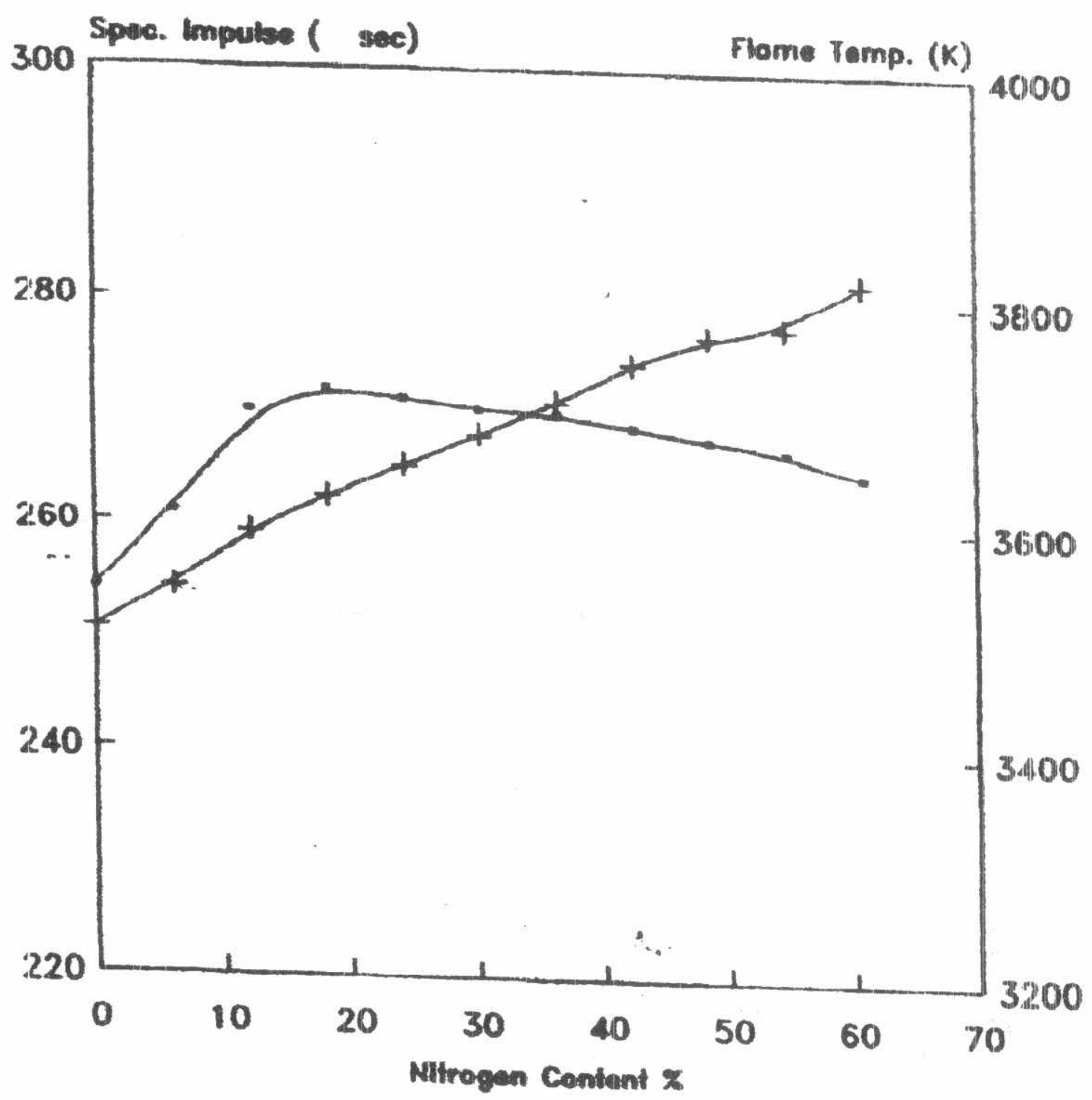

- Spactile Impulas t Adiabotic Flame Temp

Fig. 4 Dependence of Specific Imapulse and Adiabatic Flame Temperature On Nitrogen Content 